\title{
Septins in Stem Cells
}

\author{
Tanja Schuster and Hartmut Geiger* \\ Institute of Molecular Medicine, Ulm University, Ulm, Germany
}

Septins were first described in yeast. Due to extensive research in non-yeast cells, Septins are now recognized across all species as important players in the regulation of the cytoskeleton, in the establishment of polarity, for migration, vesicular trafficking and scaffolding. Stem cells are primarily quiescent cells, and this actively maintained quiescent state is critical for proper stem cell function. Equally important though, stem cells undergo symmetric or asymmetric division, which is likely linked to the level of symmetry found in the mother stem cell. Due to the ability to organize barriers and be able to break symmetry in cells, Septins are thought to have a significant impact on organizing quiescence as well as the mode (symmetric vs asymmetric) of stem cell division to affect self-renewal versus differentiation. Mechanisms of regulating mammalian quiescence and symmetry breaking by Septins are though still somewhat elusive. Within this overview article, we summarize current knowledge on the role of Septins in stem cells ranging from yeast to mice especially with respect to quiescence and asymmetric division, with a special

\section{OPEN ACCESS}

Edited by:

Hitoshi Takizawa,

Kumamoto University, Japan

Reviewed by:

Ayako Nakamura-Ishizu,

Tokyo Women's Medical University, Japan

Dirk Loeffler,

St. Jude Children's Research Hospital, United States

${ }^{*}$ Correspondence: Hartmut Geiger hartmut.geiger@uni-ulm.de

Specialty section: This article was submitted to Signaling,

a section of the journal Frontiers in Cell and Developmental Biology

Received: 25 October 2021 Accepted: 24 November 2021 Published: 09 December 2021

Citation: Schuster T and Geiger H (2021) Septins in Stem Cells. Front. Cell Dev. Biol. 9:801507. doi: 10.3389/fcell.2021.801507 focus on hematopoietic stem cells.

Keywords: septin, Borg, Cdc42, HSC, aging, stem cells, polarity, yeast

\section{SEPTINS: A HIGHER-ORDER STRUCTURE FOR COMPLEX FUNCTIONS OF CELLS}

The first image of Septins was an electron microscopy image taken in 1976 (Byers and Goetsch, 1976), 6 years after the discovery of Septins in yeast by L. H. Hartwell (Hartwell et al., 1970). It shows the budding of Saccharomyces cerevisiae and examines the neck in cytokinesis which evolves during budding. On the inner side of the plasma membrane $10 \mathrm{~nm}$ filaments are highly ordered in a ring-like structure. Yeast has seven different Septins: Cdc11, Cdc12, Cdc3, Cdc10, Shs1, Spr3 and Spr28 (Pan et al., 2007). These Septins form palindromic hetero-octamers in the order: Cdc11/Shs1-Cdc12Cdc3-Cdc10-Cdc10-Cdc3-Cdc12-Cdc11/Shs1 (Weems et al., 2017). Spr3 and Spr28 are sporulationspecific Septins and can replace Cdc12 and Shs1, respectively (McMurray and Thorner, 2008; Heasley and McMurray, 2015). According to amino acid sequence homology mammalian Septins are separated among themselves in groups (Kinoshita, 2003). 13 different Septins can be found in animals/humans that belong to four groups: Sept3 (consisting of Sept3, Sept9, Sept12), Sept6 (consisting of Sept6, Sept8, Sept10, Sept11, Sept14), Sept2 (consisting of Sept1, Sept2, Sept4, Sept5) and Sept7 (consisting of Sept7). It is evident that Sept7 is a special group as it only has one member. Septins can form hetero-oligomer filaments and the Kinoshita rule states that a Septin of a group can be exchanged by another Septin of the same group within these filaments which do have a canonical order with Sept7-Sept6-Sept2-Sept9, and can form hexamers (Sept2-Sept6-Sept7-Sept7-Sept6-Sept2) and octamers (Sept2-Sept6-Sept7-Sept9-Sept9-Sept7-Sept6-Sept2) (McMurray and Thorner, 2019; Mendonça et al., 2019; Soroor et al., 2021), but other orders of Septin groups were also reported (Sandrock et al., 2011). The hexamers and octamers can interact with each other and form higherorder structures by end-to-end joining or filament pairing by N-termini face (Jiao et al., 2020) or postulated antiparallel homodimeric coiled-coils (Leonardo et al., 2021) resulting in longer and 
TABLE1 | Septins in HSCs.

Septin type

Sept1 Ni et al. (2019)

Sept6 Senger et al. (2017)

Sept7 Kandi et al. (2021)
Phenotype in HSCs

Murine HSC

modification

Sept1 phosphorylation elevated, impaired cytoskeletal remodeling, decreased cell rigidity, stem cell egress from niche,

HSCs with enhanced mobility, decreased quiescence, increased apoptosis and defective reconstitution capacity

Increased engraftment of Sept6 ${ }^{-/-}$HSCs upon transplantation, decreased contribution to T cells and increased contribution Sept6 ${ }^{-/-}$HSCs $^{-}$

to B cells, no influence on cell cycle kinetics, cell cycle status, homing, stress tolerance

Sept7 polarity is regulated by Cdc42 activity; regulation of Cdc42-Borg4-Sept7 interaction in HSCs by Cdc42 activity level

Sept $7^{-/-}$and Borg $4^{-/-}$HSCs present impaired function upon transplantation and show changed Cdc42 distribution

Sept $7^{-1-}$ HSCs: impaired proliferation, loss of HSC and progenitor potential upon cell division
Ptpn21 $1^{-/-}$HSCs

Control HSCs

Sept $7^{-/-}$HSCs

Borg $^{-/-}$HSCs thicker nonpolar polypeptide filaments or rings (Caviston et al., 2003), gauzes (Garcia et al., 2011) and cages (Lobato-Márquez et al., 2021). High-order Septin structures are more stable than other dynamic cytoskeletal polymers (Hagiwara et al., 2011; Bridges et al., 2014) which makes Septins a good choice for acting both as barriers or scaffolds.

Interestingly though, Septins can be organized in multiple types of structures, implying a versatile but also likely a cell type-specific organization of Septins to serve a special purpose within a cell. Septins show spot-like and blob-like distributions within cells under certain conditions (isolated BD3 domain expression of Borg3 (Joberty et al., 2001)) and in certain cell types as well (Kandi et al., 2021) which are likely not linked to fibers. The ring structure of Septins is associated with cytokinesis in yeast, but Septin rings are also formed around internalized bacteria upon infection of mammalian cell lines with Listeria and Shigella bacteria (Mostowy et al., 2009) and intra-cytosolic Shigella are compartmentalized in Septin cage-like structures for autophagy as a host defense (Mostowy et al., 2010). There is a functional interdependence between Septin and Actin cytoskeleton resulting in O- and C-shaped rings as well as bundles of Septins (Schmidt and Nichols, 2004), and Septins can co-align with microtubules to form bundles (Targa et al., 2019). Arc-shaped (together with ring-like) colocalizing clusters of Sept7, Sept5 and Sept11 could be found in neurons at the base of dendritic spines with the function of building a diffusion barrier for membrane proteins (Xie et al., 2007; Ewers et al., 2014). While Septins are known for their ability to break symmetry within cells (Spiliotis and McMurray, 2020), little is known about the role of Septins in mammalian stem cells. They are though designated candidates for being involved in the organization of symmetry and polarity and thus function of stem cells.

The process of blood cell formation (which is termed hematopoiesis) depends on hematopoietic stem cells (HSCs). Roughly $75 \%$ of HSCs are in the quiescent G0 state, about $20 \%$ are in $\mathrm{G} 1,<2 \%$ can be found in an activecycling state (G2/S/M) (Cheshier et al., 1999; Wilson et al., 2008). Symmetry in quiescent, resting HSCs has been defined by the distribution of polarity proteins and nuclear markers within HSCs (Florian and Geiger, 2010; Grigoryan et al., 2018). In addition, the extent of this symmetry correlates with the age of the HSCs. With respect to the distribution of Septins within HSCs, recent published data show that both spots and blobs of certain Septins (Sept7, Sept6, Sept2) are found within HSCs (Senger et al., 2017; Kandi et al., 2021b, see Table1). The distinct roles of these specific structures (spots, blobs) remain elusive.

In young HSCs (from mice that are 4 months old) there is a polar distribution of the polarity proteins RhoGTPase Cell division control 42 protein (Cdc42), Histone 4 Lysine 16 acetylation (H4K16ac), Per2, Numb, Tubulin and also Sept7, with usually one big blob at one spot with perhaps several smaller spots, while in aged HSCs (from animals 18 months and older), this distribution is apolar: more smaller spots, and a much more dispersed distribution (Figure 1B). It is thought that the level of polarity is linked to the mode (symmetric/asymmetric) of stem cell division to balance self-renewal versus differentiation (Florian et al., 2018) and to regulate the homing capability to allow for successful immune system reconstitution after transplantation (Liang et al., 2005; Janzen et al., 2006; Florian and Geiger, 2010; Dykstra et al., 2011; Florian et al., 2012; Sun et al., 2014; Kandi et al., 2021).

Upon aging, the activity of the small RhoGTPase Cdc42, in itself also a polarity protein, is elevated in almost all tissue analyzed so far (Yang et al., 2007b; Florian et al., 2012). This elevated activity of Cdc42 causes a reduced frequency of polar HSCs among aged HSCs. Cdc42 can bind to the effector protein group binders of Rho GTPases (Borgs), which themselves were shown to interact with Septins (Joberty et al., 2001; Sheffield et al., 2003). However, it is neither completely understood how the organization and reorganization of HSCs occurs with respect to Cdc42 and Borgs, nor how the Septin network behaves and changes upon aging in HSCs.

\section{DECIPHER SEPTIN CONTRIBUTION TO MAMMALIAN STEM CELLS AND AGING VIA YEAST}

\section{Yeast as Role Model for Stem Cells?}

As there is more information on Septins in yeast, findings in yeast might inform on Septin biology also in mammalian HSCs. This will help in formulating open questions that need to be addressed in the future. Yeast possesses characteristic traits of stem cells: quiescence and asymmetric division (Werner-Washburne et al., 1993; Gray et al., 2004; Higuchi-Sanabria et al., 2014). In the past, yeast has already successfully been taken as a comparison model for metabolic changes in quiescence entry and exit (Dhawan and Laxman, 2015). Replicative life span and chronological life span 


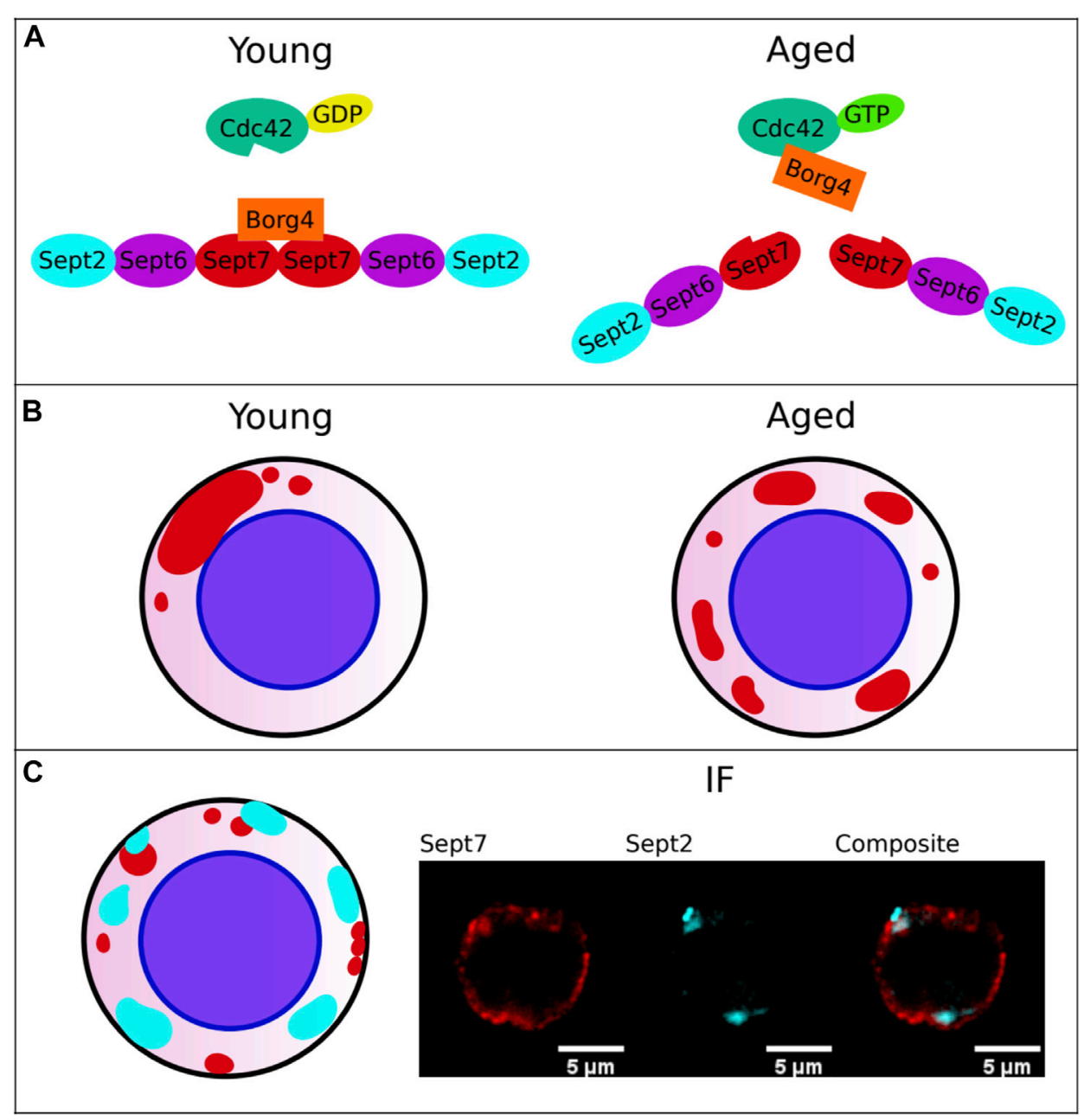

FIGURE 1 | Septin behavior in hematopoietic stem cells (HSCs). (A) Change in Cdc42-Borg4-Sept7 axis upon aging. Interaction of Borg4 with Sept7 is shifted upon aging according to elevated activity level of Cdc42 to interaction of Cdc42 with Borg4. (B) Change in protein distribution of Sept7 upon aging: Elevated Cdc42 activity leads to a more apolar distribution. (C) Interaction of Septins among themselves. Sept7 and Sept2 don't show same distribution. The Septin Network is more complex and demands further studies.

can be straightforward examined in yeast (Postnikoff and Harkness, 2014). Elevated activity of Cdc42 is linked to aging in HSCs and to replicative lifespan in yeast (Kang et al., 2021). Thus, yeast is both a good stem cell and aging model from which processes involved in impairing functions upon aging could be translated into HSCs. This could lead to clinical translations in improving transplantation success and immune system.

On the other hand, there are of course also distinct roles for Septins in yeast and HSCs. Septins for example are indispensable for yeast division (Hartwell et al., 1970), yet especially for the hematopoietic system it was shown that cytokinesis may occur without Septins, while Septins are indispensable for cytokinesis in fibroblasts (Menon et al., 2014). Novel anti-Septin cancer drugs for solid tumors might thus benefit from the fact that Septins are dispensable for hematopoietic cytokinesis while being critical for cancer cells (Menon and Gaestel, 2015). In summary, published data imply that while yeast can serve as a stem cell model and inform on roles of Septins in HSCs, Septins also show a cell type- specific behavior, which requires a careful approach when translating findings in yeast to HSCs.

\section{Quiescence}

Quiescence is a cell state in which cells exit the cell cycle and rest in a more robust, withstanding state (G0) till they respond to a signal and reenter the cell cycle. Features of quiescence spanning across species are: reduction of cell size, arrest of cell cycle, condensation of chromosomes, reduction of rRNA synthesis and reduction of protein translation, increase in autophagic activity and increase in stress resistance (Hendil, 1981; Kniss and Burry, 1988; Nagele et al., 1999; Kops et al., 2002; Yusuf and Fruman, 2003; Zhang et al., 2003; Gray et al., 2004; Dhawan and Laxman, 2015; Roche et al., 2017; Wang et al., 2017; Sun and Gresham, 2021).

Many types of extrinsic and intrinsic signals maintain HSCs in quiescence (Liu et al., 2009; Matsumoto et al., 2011; Yamazaki et al., 2011; Nakamura-Ishizu et al., 2014). 
As HSC quiescence entry and exit is dependent on the conversion of the cytoskeleton, changes in the localization and structure of organelles will thus likely depend on the well-known properties of Septins like organizing, scaffolding and barricading. Currently, there is no direct data on the role of Septins upon HSCs leaving or entering the quiescent state. The role of Septins in quiescent yeast cells might thus help to inform on likely roles of Septins in quiescent mammalian HSCs.

Yeast enters the quiescent state upon nutrient deprivation or desiccation and several pathways like Target of rapamycin complex I (TORC1), Sucrose non-fermenting 1 (SNF1) protein kinase, Protein kinase A (PKA) and Pho80-Pho85 (Forget et al., 2002; Sopko et al., 2007; Xu et al., 2012) all contribute to this decision. Downregulation of TORCI, a downregulation of PKA, a downregulation of Pho80-Pho85 or an upregulation of SNF1 results in entering of the quiescent state in yeast. These signals are, at the end, all integrated and feed into the regulation of the activity of Cdc42. For mammalian cells similar pathways have been reported for being responsible for the regulation of quiescence in HSCs (Chen et al., 2008; Gan et al., 2010; Cheng et al., 2014), and it was shown that Cdc42 is important for quiescence in HSCs, as the Cdc42 knockout mouse model, which though does not represent physiological Cdc42 deviations upon aging, results in HSC cycling (Yang and Zheng, 2007a).

These findings lead to the following questions with respect to the role of Septins in quiescence: 1) How is Cdc42 linked to Septins? 2) How does Cdc42 affect Septins? and 3) Do interactions of Septins with other cytoskeletal proteins change upon quiescence?

1) A whole family of interaction partners linking Cdc42 to Septins was found in 1997: Gic1 and Gic2 bind specifically to Cdc42-guanosine triphosphate (Cdc42-GTP) (Brown et al., 1997) as well as to Septins (Sadian et al., 2013). It was shown that Gic1 behaves as a scaffolding protein for Septin filaments and Cdc42GTP binding to Gic1 results in dissociation of Gic1 from Septin filaments. Cdc42-GDP can directly disassemble Septin filaments in yeast when Gicl is missing. A functional mammalian equivalent was found in 1999 by Joberty et al.: Borgs (Binder of Rho GTPases) 1-5, also entitled as Cdc42 effector proteins 1-5, bind Cdc42 in a GTP-dependent manner (Joberty et al., 1999). HSCs do also express Borg proteins (Kandi et al., 2021). Among the above mentioned pathways linked to quiescence, also Iqg1 of the yeast TORC1 pathway was shown to be involved in Septin ring organization and regulation of Cdc42 activity (Iwase et al., 2007; Atkins et al., 2013). The mammalian homologue IQGAP1 binds the Exocyst-Septin complex via its $\mathrm{N}$-terminus, probably via Sept2, and Cdc42-GTP via its C-terminus (Hedman et al., 2015; Wang et al., 2009) showing functional interdependence like regulation of secretion (Rittmeyer et al., 2008). Normal levels of Cdc42 activity (more GDP) regulate the assembly of Septin fibers via "free to bind Borgs", and Borgs lead to a stabilization and bundling of Septin filaments, which is consistent with the strong focal assembly (big blob) of Septins seen in young HSCs (Figure 1B). Such a view is further consistent with the recent finding from our laboratory that upon aging of HSCs, there is a switch in the Cdc42-Borg-Septin relationship: Elevated Cdc42 activity in aged correlated with co-localization of Cdc42 and Borg4, whereas in young HSCs (lower Cdc42 activity) Borg4 and Sept7 co-localized (Kandi et al., 2021) (Figure 1A). In conclusion, these data support that Cdc42 activity influences Septin behavior in both yeast and adult stem cells like HSCs and might also be critical for the role of Septins in quiescence.

2) Cdc42 activity changes upon quiescence as quiescence requires a downregulation of mTOR, of PKA, of Pho80-Pho85 and an upregulation of Snf1/AMPK, which altogether means more Septin-Exocyst complexes being bound to Iqg1 (mTOR, Snf1) (Xu et al., 2012), a dampened activity of Cdc42 (Pho80Pho85) (Paglini et al., 2001; Sopko et al., 2007) with more membrane-bound Cdc42 (PKA) (Forget et al., 2002; Johnson et al., 2009). In summary, there is indeed a switch of Septin-Gic/ Borg interactions regulated by Cdc42 activity in yeast and HSCs, which influences bundling and stabilization of Septin filaments. As it has not been tested though whether Cdc42-GDP indeed disturbs Septin filaments in HSCs like it does in yeast, it still remains a possibility that the Cdc42-Borg-Septin axis is somewhat distinct between yeast and HSCs with respect to quiescence.

3) While Septins also actively participate in forming the cytoskeleton (Kinoshita et al., 2002; Mavrakis et al., 2014; Kuzmić et al., 2021), they are not directly involved in the reorganization and restructuring of Actin and microtubules upon quiescence in yeast (Sagot et al., 2006; Laporte et al., 2013; Laporte et al., 2015). However, in HSCs a link of Septins to the cytoskeleton was shown by the finding that Ptpn21 localizing to Actin filaments is important for Sept1 dephosphorylation and Sept 1 dephosphorylation level is crucial for HSC stiffness and retention in the bone marrow niche (Ni et al., 2019 and see Table1). Thus, in this case, investigations into the role of Septins in HSCs might inform on likely mechanisms of interactions of Septins with the cytoskeleton in yeast. Nonetheless, the involvement of Septins in reorganization of the other cytoskeleton components upon quiescence is still uncharted territory. An in depth understanding of the role Septins play in regulating quiescence will be important for basic stem cell biology, aging and cancer research.

\section{Asymmetric Division}

Asymmetric divisions first allow stem cells to provide a more differentiated cell that will contribute to tissue homeostasis while maintaining the pool of stem cells. Asymmetric division is also thought to be the key to produce one daughter cell which is free of already damaged products and one daughter cell which takes all these damaged products, and is regarded as kind of a rejuvenation strategy (Higuchi-Sanabria et al., 2014). Several organelles, proteins and mRNAs are asymmetrically inherited to daughters in yeast (McFaline-Figueroa et al., 2011; Shcheprova et al., 2008; Kennedy and McCormick, 2011; Henderson et al., 2014; Yang et al., 2015; Spokoini et al., 2012). The same holds true for mammalian stem cells (Inaba and Yamashita, 2012; Katajisto et al., 2015; Wang X. et al., 2009; Paridaen et al., 2013; Kuo et al., 2011; Rujano et al., 2006; Fuentealba et al., 2008; Loeffler et al., 2019; Hinge et al., 2020; Vannini et al., 2019; Loeffler at al., 2021). Proteins and organelles need to be distributed in a polar fashion 
in cells during mitosis to allow for an asymmetric split-up. Our data show that polarity/symmetry in quiescent cells correlates with the type of division mode (symmetric/asymmetric) (Florian et al., 2018). Similar findings were made for mitochondria inheritance in HSCs (Hinge et al., 2020) and inheritance of lysosomes, autophagosomes, mitophagosomes, NUMB, Notch1 and CD63 which functionally predict the activation of daughter cells and thus their fates (Loeffler et al., 2019).

As Septins are master regulators of asymmetry and polarity (Spiliotis and McMurray, 2020), it is very likely that they play a role not only in the asymmetric division of budding yeast but as well also in HSC division and general asymmetric distribution of proteins within HSCs. We could recently demonstrate that Sept7 is indeed involved in regulating the distribution of polarity proteins in HSCs (Kandi et al., 2021, see Table1). Budding yeast achieves polarity and thus asymmetry during cell cytokinesis by three consecutive steps with enduring Septin support: 1) deciding upon a bud site and 2) passage of cellular components through a barrier and 3) active retainment of components within a compartmentalized space.

1) The first step is made by landmark proteins that then activate Rsr1 at a specific location. Rsr1-GTP recruits Cdc24, which functions as guanine-nucleotide-exchange factor (GEF) for Cdc42. Cdc42 is activated by Cdc24. Cdc42 further accumulates by positive feedback mechanisms that result in an area of high density of Cdc42-GTP. Septins then move to the high density Cdc42-GTP area. Right before budding Cdc24 interacts with the Septin Cdc11, which is essential for Septin recruitment and stability of the polarity patch (Park et al., 1997; Kang et al., 2001; Shimada et al., 2004; Chollet et al., 2020). Septins then form the characteristic ring-like filaments at the bud site (Okada et al., 2013). Cdc42 activity therefore plays a role in the polarization of the Septin ring. Whether there is a ring-like structure of Septins upon initiation of division of HSCs is currently not known.

2) The second step is regulated by the Septin ring which functions like a lateral diffusion barrier and compartmentalizes the bud. Septins can via this means function as a barrier for misfolded proteins of endoplasmic reticulum (ER) in the mother cell in a Septin-, Bud1-and sphingolipid-dependent manner (Chao et al., 2014; Clay et al., 2014). Similar mechanisms are proposed for the role of Septins in neurons, in which dendritic spines are restricted in the diffusion of ER proteins (Tada et al., 2007; Xie et al., 2007). It is thus likely that Septins can also play a similar role in HSCs, and also function in HSCs both as scaffold and as barrier in the process of asymmetric divisions.

3) The third step, active retainment, is fulfilled by anchor proteins that are transported to the bud and retain transported organelles and proteins in the bud or in the mother cell. While asymmetrically inherited mRNA is transported by Actin (Munchow et al., 1999; Takizawa et al., 2000), Septins act like a diffusion barrier by holding proteins that anchor organelles to the bud tip like Mmr1. (Fehrenbacher et al., 2004; McFalineFigueroa et al., 2011; Swayne et al., 2011; Higuchi et al., 2013). Septins were also shown to interact with membrane components like phosphatidylinositol-4,5-bisphospate (PIP2). Septins are curvature-sensitive and capable of shaping the form of membranes (Gladfelter et al., 2005; Tanaka-Takiguchi et al.,
2009; Bertin et al., 2010; Beber et al., 2019; Cannon et al., 2019). It is thus a possibility that Septins form lipid scaffolds for proteins, which themselves do not interact with Septins but are retained due to specific lipid or protein composition of the lipid scaffold. Research into the interaction of the lipidome with Septins will be necessary to obtain novel information on this likely novel role of Septins in the regulation of asymmetry, also presumably in HSCs.

While there has been ample progress in understanding the role of Septins for asymmetric division in yeast, so far, there have been no investigations published on the role of Septins and the Septin network in HSCs or even other stem cells for retaining or repulsing proteins and organelles upon division. Mammalian stem cell research has been focused on the role of individual Septins and their role for organelles. A disruption of mitochondrial fission in human mammary stem-like cells leads to symmetrical inheritance (Katajisto et al., 2015). A Drp1mediated, distinct localization of old mitochondria is important for this asymmetric inheritance (Hinge et al., 2020). Sept2 is a known Drp1 interaction partner involved in mitochondria fission, implying indeed that Sept2 might be involved in an asymmetric inheritance of mitochondria upon division (Pagliuso et al., 2016). Centriole and cilium inheritance is asymmetric in radial glial progenitor cells (Wang X. et al., 2009; Paridaen et al., 2013). As Sept7 is a centrosomal protein and is involved in the process of mitotic spindle pole formation (Chen et al., 2021), it is possible that it also plays a role in asymmetric inheritance of centrioles and primary cilium in progenitor cells. A main unsolved question remains the nature of the role of the Septin network and thus filaments in HSCs and even in yeast. While the function of Septins has been frequently linked to their function within the filament network, recent data from our laboratory imply a non-filament linked, distinct polar/apolar distribution of Sept7, Sept2 and Sept6 in HSCs (Kandi et al., 2021b). For example, the distribution of Sept7 and Sept 2 in HSCs is quite distinct (Figure 1C), which questions whether these Septins are indeed strongly interacting. Novel research on the role of Septins for the division of HSCs will thus need to focus on both the role of the Septin network as well as the role of individual Septins.

\section{PERSPECTIVES}

While Septins have been investigated since the early 1970s, even after now more than these 50 years of Septin research, the Septin field is still an emerging field with recent novel exciting developments like a revisited order of human Septins (instead of the previously postulated hexamer form "Sept7-Sept6-Sept2Sept2-Sept6-Sept7" the novel hexamer form reads "Sept2-Sept6Sept7-Sept7-Sept6-Sept2" and instead of the postulated octamer form "Sept9-Sept7-Sept6-Sept2-Sept2-Sept6-Sept7-Sept9" the novel octamer form reads "Sept2-Sept6-Sept7-Sept9-Sept9Sept7-Sept6-Sept2"). (McMurray and Thorner, 2019; Mendonça et al., 2019; Soroor et al., 2021). So far, little is known about the role of Septins in maintenance of quiescence in yeast and stem cells, while the same holds true for the role of 
Septins in asymmetric division and asymmetric protein distribution in stem cells. The role of Septins for an asymmetric division in yeast has been extensively studied, and in general, Septin biology in yeast might thus serve indeed as an initial blueprint for Septins in other types of stem cells like HSCs.

It is becoming more and more obvious though that Septins act also very cell type-specific, and have specific functions in distinct types of cells, especially among differentiated cells or cell lines. It will become therefore critical to investigate the role of Septins in a variety of cell types in order to understand their distinct behavior and to initiate transition of knowledge for example to drug development approaches to harvest differential sensitivities of cells to drugs targeting specific Septins (Menon and Gaestel, 2015). Another critical question that requires more attention is the organization state of Septins within cells, as both Septin filaments but also individual Septins outside of filaments are likely to have major biological function. Novel proteomics, lipidomics and immunofluorescence approaches that work on a few or even single cells will support the hunt for interaction partners of Septins and the organization of the Septin network in rare stem cells. It is likely that stem cells, due to their requirement of balancing

\section{REFERENCES}

Atkins, B. D., Yoshida, S., Saito, K., Wu, C.-F., Lew, D. J., and Pellman, D. (2013). Inhibition of Cdc42 during Mitotic Exit Is Required for Cytokinesis. J. Cel Biol 202, 231-240. doi:10.1083/jcb.201301090

Beber, A., Taveneau, C., Nania, M., Tsai, F.-C., Di Cicco, A., Bassereau, P., et al. (2019). Membrane Reshaping by Micrometric Curvature Sensitive Septin Filaments. Nat. Commun. 10, 420. doi:10.1038/s41467-019-08344-5

Bertin, A., McMurray, M. A., Thai, L., Garcia, G., Votin, V., Grob, P., et al. (2010). Phosphatidylinositol-4,5-bisphosphate Promotes Budding Yeast Septin Filament Assembly and Organization. J. Mol. Biol. 404, 711-731. doi:10.1016/j.jmb.2010.10.002

Bridges, A. A., Zhang, H., Mehta, S. B., Occhipinti, P., Tani, T., and Gladfelter, A. S. (2014). Septin Assemblies Form by Diffusion-Driven Annealing on Membranes. Proc. Natl. Acad. Sci. USA 111, 2146-2151. doi:10.1073/ pnas. 1314138111

Brown, J. L., Jaquenoud, M., Gulli, M.-P., Chant, J., and Peter, M. (1997). Novel Cdc42-Binding Proteins Gic1 and Gic2 Control Cell Polarity in Yeast. Genes Dev. 11, 2972-2982. doi:10.1101/gad.11.22.2972

Byers, B., and Goetsch, L. (1976). A Highly Ordered Ring of Membrane-Associated Filaments in Budding Yeast. J. Cel. Biol. 69, 717-721. doi:10.1083/jcb.69.3.717

Cannon, K. S., Woods, B. L., Crutchley, J. M., and Gladfelter, A. S. (2019). An Amphipathic helix Enables Septins to Sense Micrometer-Scale Membrane Curvature. J. Cel Biol 218, 1128-1137. doi:10.1083/jcb.201807211

Carolina Florian, M., and Geiger, H. (2010). Concise Review: Polarity in Stem Cells, Disease, and Aging. Stem cells 28, 1623-1629. doi:10.1002/stem.481

Caviston, J. P., Longtine, M., Pringle, J. R., and Bi, E. (2003). The Role of Cdc42p Gtpase-Activating Proteins in Assembly of the Septin Ring in Yeast. MBoC 14, 4051-4066. doi:10.1091/mbc.e03-04-0247

Chao, J. T., Wong, A. K. O., Tavassoli, S., Young, B. P., Chruscicki, A., Fang, N. N., et al. (2014). Polarization of the Endoplasmic Reticulum by Er-Septin Tethering. Cell 158, 620-632. doi:10.1016/j.cell.2014.06.033

Chen, C., Liu, Y., Liu, R., Ikenoue, T., Guan, K.-L., Liu, Y., et al. (2008). Tsc-mtor Maintains Quiescence and Function of Hematopoietic Stem Cells by Repressing Mitochondrial Biogenesis and Reactive Oxygen Species. J. Exp. Med. 205, 2397-2408. doi:10.1084/jem.20081297

Chen, T. Y., Lin, T. C., Kuo, P. L., Chen, Z. R., Cheng, H. 1., Chao, Y. Y., et al. (2021). Septin 7 Is a Centrosomal Protein that Ensures S Phase Entry and Microtubule Nucleation by Maintaining the Abundance of P150 Glued. J. Cel Physiol 236, 2706-2724. doi:10.1002/jcp.30037 quiescence and cycling and symmetric and asymmetric division might provide a fertile ground for elucidating these complex and context-dependent roles already within 1 cell type, as the underlying complexity that requires a versatile function of Septins might likely not be found in differentiated cells.

\section{AUTHOR CONTRIBUTIONS}

TS and HG wrote the manuscript.

\section{FUNDING}

TS is supported by the RTG 1789 CEMMA funded by the DFG.

\section{ACKNOWLEDGMENTS}

We thank the members of the Geiger lab for the input on the manuscript.

Cheng, C.-W., Adams, G. B., Perin, L., Wei, M., Zhou, X., Lam, B. S., et al. (2014) Prolonged Fasting Reduces Igf-1/pka to Promote Hematopoietic-Stem-CellBased Regeneration and Reverse Immunosuppression. Cell stem cell 14, 810-823. doi:10.1016/j.stem.2014.04.014

Cheshier, S. H., Morrison, S. J., Liao, X., and Weissman, I. L. (1999). In Vivo proliferation and Cell Cycle Kinetics of Long-Term Self-Renewing Hematopoietic Stem Cells. Proc. Natl. Acad. Sci. 96, 3120-3125. doi:10.1073/ pnas.96.6.3120

Chollet, J., Dünkler, A., Bäuerle, A., Vivero-Pol, L., Mulaw, M. A., Gronemeyer, T., et al. (2020). Cdc24 Interacts with Septins to Create a Positive Feedback Loop during Bud Site Assembly in Yeast. J. Cel Sci 133, jcs240283. doi:10.1242/ jcs. 240283

Clay, L., Caudron, F., Denoth-Lippuner, A., Boettcher, B., Buvelot Frei, S., Snapp, E. L., et al. (2014). A Sphingolipid-dependent Diffusion Barrier Confines Er Stress to the Yeast Mother Cell. Elife 3, e01883. doi:10.7554/eLife.01883

Dhawan, J., and Laxman, S. (2015). Decoding the Stem Cell Quiescence Cycle Lessons from Yeast for Regenerative Biology. J. Cel. Sci. 128, 4467-4474. doi: $10.1242 /$ jcs. 177758

Dykstra, B., Olthof, S., Schreuder, J., Ritsema, M., and De Haan, G. (2011). Clonal Analysis Reveals Multiple Functional Defects of Aged Murine Hematopoietic Stem Cells. J. Exp. Med. 208, 2691-2703. doi:10.1084/jem.20111490

Ewers, H., Tada, T., Petersen, J. D., Racz, B., Sheng, M., and Choquet, D. (2014). A Septin-dependent Diffusion Barrier at Dendritic Spine Necks. PloS one 9, e113916. doi:10.1371/journal.pone.0113916

Fehrenbacher, K. L., Yang, H.-C., Gay, A. C., Huckaba, T. M., and Pon, L. A. (2004). Live Cell Imaging of Mitochondrial Movement along Actin Cables in Budding Yeast. Curr. Biol. 14, 1996-2004. doi:10.1016/j.cub.2004.11.004

Florian, M. C., Dörr, K., Niebel, A., Daria, D., Schrezenmeier, H., Rojewski, M., et al. (2012). Cdc42 Activity Regulates Hematopoietic Stem Cell Aging and Rejuvenation. Cell stem cell 10, 520-530. doi:10.1016/j.stem.2012.04.007

Florian, M. C., Klose, M., Sacma, M., Jablanovic, J., Knudson, L., Nattamai, K. J., et al. (2018). Aging Alters the Epigenetic Asymmetry of HSC Division. Plos Biol. 16 (9), e2003389. doi:10.1371/journal.pbio.2003389

Forget, M.-A., Desrosiers, R. R., Gingras, D., and Béliveau, R. (2002). Phosphorylation States of $\mathrm{Cdc} 42$ and Rhoa Regulate Their Interactions with Rho Gdp Dissociation Inhibitor and Their Extraction from Biological Membranes. Biochem. J. 361, 243-254. doi:10.1042/bj3610243

Fuentealba, L. C., Eivers, E., Geissert, D., Taelman, V., and De Robertis, E. M. (2008). Asymmetric Mitosis: Unequal Segregation of Proteins Destined for Degradation. Proc. Natl. Acad. Sci. 105, 7732-7737. doi:10.1073/ pnas.0803027105 
Gan, B., Hu, J., Jiang, S., Liu, Y., Sahin, E., Zhuang, L., et al. (2010). Lkb1 Regulates Quiescence and Metabolic Homeostasis of Haematopoietic Stem Cells. Nature 468, 701-704. doi:10.1038/nature09595

Garcia, G., Bertin, A., Li, Z., Song, Y., McMurray, M. A., Thorner, J., et al. (2011). Subunit-dependent Modulation of Septin Assembly: Budding Yeast Septin Shs1 Promotes Ring and Gauze Formation. J. Cel Biol 195, 993-1004. doi:10.1083/ jcb.201107123

Gladfelter, A. S., Kozubowski, L., Zyla, T. R., and Lew, D. J. (2005). Interplay between Septin Organization, Cell Cycle and Cell Shape in Yeast. J. Cel. Sci. 118, 1617-1628. doi:10.1242/jcs.02286

Gray, J. V., Petsko, G. A., Johnston, G. C., Ringe, D., Singer, R. A., and WernerWashburne, M. (2004). "sleeping beauty": Quiescence in saccharomyces Cerevisiae. Microbiol. Mol. Biol. Rev. 68, 187-206. doi:10.1128/ mmbr.68.2.187-206.2004

Grigoryan, A., Guidi, N., Senger, K., Liehr, T., Soller, K., Marka, G., et al. (2018). LaminA/C Regulates Epigenetic and Chromatin Architecture Changes upon Aging of Hematopoietic Stem Cells. Genome Biol. 19, 189. doi:10.1186/s13059-018-1557-3

Hagiwara, A., Tanaka, Y., Hikawa, R., Morone, N., Kusumi, A., Kimura, H., et al. (2011). Submembranous Septins as Relatively Stable Components of ActinBased Membrane Skeleton. Cytoskeleton 68, 512-525. doi:10.1002/cm.20528

Hartwell, L. H., Culotti, J., and Reid, B. (1970). Genetic Control of the Cell-Division Cycle in Yeast, I. Detection of Mutants. Proc. Natl. Acad. Sci. 66, 352-359. doi:10.1073/pnas.66.2.352

Heasley, L. R., and McMurray, M. A. (2016). Roles of Septins in Prospore Membrane Morphogenesis and Spore wall Assembly inSaccharomyces Cerevisiae. MBoC 27, 442-450. doi:10.1091/mbc.e15-10-0721

Hedman, A. C., Smith, J. M., and Sacks, D. B. (2015). The Biology of IQGAP Proteins: beyond the Cytoskeleton. EMBO Rep. 16, 427-446. doi:10.15252/ embr.201439834

Henderson, K. A., Hughes, A. L., and Gottschling, D. E. (2014). Mother-daughter Asymmetry of Ph Underlies Aging and Rejuvenation in Yeast. Elife 3, e03504. doi:10.7554/eLife.03504

Hendil, K. B. (1981). Autophagy of Metabolically Inert Substances Injected into Fibroblasts in Culture. Exp. Cel. Res. 135, 157-166. doi:10.1016/0014-4827(81) 90308-6

Higuchi, R., Vevea, J. D., Swayne, T. C., Chojnowski, R., Hill, V., Boldogh, I. R., et al. (2013). Actin Dynamics Affect Mitochondrial Quality Control and Aging in Budding Yeast. Curr. Biol. 23, 2417-2422. doi:10.1016/j.cub.2013.10.022

Higuchi-Sanabria, R., Pernice, W. M. A., Vevea, J. D., Alessi Wolken, D. M., Boldogh, I. R., and Pon, L. A. (2014). Role of Asymmetric Cell Division in Lifespan Control inSaccharomyces Cerevisiae. FEMS Yeast Res. 14, 1133-1146. doi:10.1111/1567-1364.12216

Hinge, A., He, J., Bartram, J., Javier, J., Xu, J., Fjellman, E., et al. (2020). Asymmetrically Segregated Mitochondria Provide Cellular Memory of Hematopoietic Stem Cell Replicative History and Drive HSC Attrition. Cell Stem CellPMCID 26 (3), 420PMC7212526-430. doi:10.1016/j.stem.2020.01.016

Inaba, M., and Yamashita, Y. M. (2012). Asymmetric Stem Cell Division: Precision for Robustness. Cell stem cell 11, 461-469. doi:10.1016/j.stem.2012.09.003

Iwase, M., Luo, J., Bi, E., and Toh-e, A. (2007). Shs1 Plays Separable Roles in Septin Organization and Cytokinesis in Saccharomyces cerevisiae. Genetics 177, 215-229. doi:10.1534/genetics.107.073007

Janzen, V., Forkert, R., Fleming, H. E., Saito, Y., Waring, M. T., Dombkowski, D. M., et al. (2006). Stem-cell Ageing Modified by the Cyclin-dependent Kinase Inhibitor p16INK4a. Nature 443, 421-426. doi:10.1038/nature05159

Jiao, F., Cannon, K. S., Lin, Y.-C., Gladfelter, A. S., and Scheuring, S. (2020). The Hierarchical Assembly of Septins Revealed by High-Speed Afm. Nat. Commun. 11, 5062. doi:10.1038/s41467-020-18778-x

Joberty, G., Perlungher, R. R., and Macara, I. G. (1999). The Borgs, a New Family of Cdc42 and Tc10 Gtpase-Interacting Proteins. Mol. Cel Biol 19, 6585-6597. doi:10.1128/mcb.19.10.6585

Joberty, G., Perlungher, R. R., Sheffield, P. J., Kinoshita, M., Noda, M., Haystead, T., et al. (2001). Borg Proteins Control Septin Organization and Are Negatively Regulated by Cdc42. Nat. Cel Biol 3, 861-866. doi:10.1038/ncb1001-861

Johnson, J. L., Erickson, J. W., and Cerione, R. A. (2009). New Insights into How the Rho Guanine Nucleotide Dissociation Inhibitor Regulates the Interaction of Cdc42 with Membranes. J. Biol. Chem. 284, 23860-23871. doi:10.1074/ jbc.m109.031815
Kandi, R., Senger, K., Grigoryan, A., Soller, K., Sakk, V., Schuster, T., et al. (2021b). A Cdc42-Borg4-Septin 7 axis Regulates HSCs Polarity and Function. bioRxiv. doi:10.1101/2021.03.17.435817

Kandi, R., Senger, K., Grigoryan, A., Soller, K., Sakk, V., Schuster, T., et al. (2021). Cdc42-Borg4-Septin7 axis Regulates HSC Polarity and Function. EMBO Rep., e52931. doi:10.15252/embr.202152931

Kang, P. J., Mullner, R., Li, H., Hansford, D., Shen, H.-W., and Park, H.-O. (2021). Upregulation of the Cdc42 GTPase Limits Replicative Lifespan in Budding Yeast. bioRxiv. doi:10.1101/2021.04.27.441634

Kang, P. J., Sanson, A., Lee, B., and Park, H.-O. (2001). A GDP/GTP Exchange Factor Involved in Linking a Spatial Landmark to Cell Polarity. Science 292, 1376-1378. doi:10.1126/science. 1060360

Katajisto, P., Döhla, J., Chaffer, C. L., Pentinmikko, N., Marjanovic, N., Iqbal, S., et al. (2015). Asymmetric Apportioning of Aged Mitochondria between Daughter Cells Is Required for Stemness. Science 348, 340-343. doi:10.1126/ science. 1260384

Kennedy, B. K., and McCormick, M. A. (2011). Asymmetric Segregation: the Shape of Things to Come? Curr. Biol. 21, R149-R151. doi:10.1016/j.cub.2011.01.018

Kinoshita, M. (2003). Assembly of Mammalian Septins. J. Biochem. 134, 491-496. doi:10.1093/jb/mvg182

Kinoshita, M., Field, C. M., Coughlin, M. L., Straight, A. F., and Mitchison, T. J. (2002). Self- and Actin-Templated Assembly of Mammalian Septins. Develop. Cel. 3, 791-802. doi:10.1016/s1534-5807(02)00366-0

Kniss, D. A., and Burry, R. W. (1988). Serum and Fibroblast Growth Factor Stimulate Quiescent Astrocytes to Re-enter the Cell Cycle. Brain Res. 439, 281-288. doi:10.1016/0006-8993(88)91485-0

Kops, G. J. P. L., Dansen, T. B., Polderman, P. E., Saarloos, I., Wirtz, K. W. A., Coffer, P. J., et al. (2002). Forkhead Transcription Factor Foxo3a Protects Quiescent Cells from Oxidative Stress. Nature 419, 316-321. doi:10.1038/ nature 01036

Kuo, T.-C., Chen, C.-T., Baron, D., Onder, T. T., Loewer, S., Almeida, S., et al. (2011). Midbody Accumulation through Evasion of Autophagy Contributes to Cellular Reprogramming and Tumorigenicity. Nat. Cel Biol 13, 1214-1223. doi:10.1038/ncb2332

Kuzmić, M., Linares, G. C., Fialova', J. L., Iv, F., Salau“n, D., Llewellyn, A., et al. (2021). Septin Microtubule Association Requires a Map-like Motif Unique to Sept9 Isoform 1 Embedded into Septin Octamers. BioRxiv.

Laporte, D., Courtout, F., Pinson, B., Dompierre, J., Salin, B., Brocard, L., et al. (2015). A Stable Microtubule Array Drives Fission Yeast Polarity Reestablishment upon Quiescence Exit. J. Cel Biol. 210, 99-113. doi:10.1083/ jcb.201502025

Laporte, D., Courtout, F., Salin, B., Ceschin, J., and Sagot, I. (2013). An Array of Nuclear Microtubules Reorganizes the Budding Yeast Nucleus during Quiescence. J. Cel Biol. 203, 585-594. doi:10.1083/jcb.201306075

Leonardo, D. A., Cavini, I. A., Sala, F. A., Mendonça, D. C., Rosa, H. V. D., Kumagai, P. S., et al. (2021). Orientational Ambiguity in Septin Coiled Coils and its Structural Basis. J. Mol. Biol. 433, 166889. doi:10.1016/ j.jmb.2021.166889

Liang, Y., Van Zant, G., and Szilvassy, S. J. (2005). Effects of Aging on the Homing and Engraftment of Murine Hematopoietic Stem and Progenitor Cells. Blood 106, 1479-1487. doi:10.1182/blood-2004-11-4282

Liu, Y., Elf, S. E., Miyata, Y., Sashida, G., Liu, Y., Huang, G., et al. (2009). p53 Regulates Hematopoietic Stem Cell Quiescence. Cell stem cell 4, 37-48. doi:10.1016/j.stem.2008.11.006

Lobato-Márquez, D., Xu, J., Güler, G. Ö., Ojiakor, A., Pilhofer, M., and Mostowy, S. (2021). Mechanistic Insight into Bacterial Entrapment by Septin Cage Reconstitution. Nat. Commun. 12, 4511. doi:10.1038/s41467-021-24721-5

Loeffler, D., Schneiter, F., Wang, W., Wehling, A., Kull, T., Lengerke, C., et al. (2021). Asymmetric Organelle Inheritance Predicts Human Blood Stem Cell Fate. Blood, blood, 2020009778. doi:10.1182/blood.2020009778

Loeffler, D., Wehling, A., Schneiter, F., Zhang, Y., Müller-Bötticher, N., Hoppe, P. S., et al. (2019). Asymmetric Lysosome Inheritance Predicts Activation of Haematopoietic Stem Cells. Nature 573, 426-429. doi:10.1038/s41586-019-1531-6

Matsumoto, A., Takeishi, S., Kanie, T., Susaki, E., Onoyama, I., Tateishi, Y., et al. (2011). p57 Is Required for Quiescence and Maintenance of Adult Hematopoietic Stem Cells. Cell stem cell 9, 262-271. doi:10.1016/ j.stem.2011.06.014 
Mavrakis, M., Azou-Gros, Y., Tsai, F.-C., Alvarado, J., Bertin, A., Iv, F., et al. (2014). Septins Promote F-Actin Ring Formation by Crosslinking Actin Filaments into Curved Bundles. Nat. Cel Biol 16, 322-334. doi:10.1038/ncb2921

McFaline-Figueroa, J. R., Vevea, J., Swayne, T. C., Zhou, C., Liu, C., Leung, G., et al. (2011). Mitochondrial Quality Control during Inheritance Is Associated with Lifespan and Mother-Daughter Age Asymmetry in Budding Yeast. Aging cell 10, 885-895. doi:10.1111/j.1474-9726.2011.00731.x

McMurray, M. A., and Thorner, J. (2008). Septin Stability and Recycling during Dynamic Structural Transitions in Cell Division and Development. Curr. Biol. 18, 1203-1208. doi:10.1016/j.cub.2008.07.020

McMurray, M. A., and Thorner, J. (2019). Turning it inside Out: the Organization of Human Septin Heterooligomers. Cytoskeleton 76, 449-456. doi:10.1002/ $\mathrm{cm} .21571$

Mendonça, D. C., Macedo, J. N., Guimarães, S. L., Barroso da Silva, F. L., Cassago, A., Garratt, R. C., et al. (2019). A Revised Order of Subunits in Mammalian Septin Complexes. Cytoskeleton (Hoboken) 76, 457-466. doi:10.1002/cm.21569

Menon, M. B., and Gaestel, M. (2015). Sep(t)arate or Not - How Some Cells Take Septin-independent Routes through Cytokinesis. J. Cel. Sci. 128, 1877-1886. doi: $10.1242 /$ jcs. 164830

Menon, M. B., Sawada, A., Chaturvedi, A., Mishra, P., Schuster-Gossler, K., Galla, M., et al. (2014). Genetic Deletion of Sept7 Reveals a Cell Type-specific Role of Septins in Microtubule Destabilization for the Completion of Cytokinesis. Plos Genet. 10, e1004558. doi:10.1371/journal.pgen.1004558

Mostowy, S., Bonazzi, M., Hamon, M. A., Tham, T. N., Mallet, A., Lelek, M., et al. (2010). Entrapment of Intracytosolic Bacteria by Septin Cage-like Structures. Cell Host \& Microbe 8, 433-444. doi:10.1016/j.chom.2010.10.009

Mostowy, S., Nam Tham, T., Danckaert, A., Guadagnini, S., Boisson-Dupuis, S., Pizarro-Cerdá, J., et al. (2009). Septins Regulate Bacterial Entry into Host Cells. PloS one 4, e4196. doi:10.1371/journal.pone.0004196

Munchow, S., Sauter, C., and Jansen, R. P. (1999). Association of the Class V Myosin Myo4p with a Localised Messenger Rna in Budding Yeast Depends on She Proteins. J. Cel. Sci. 112, 1511-1518. doi:10.1242/jcs.112.10.1511

Nagele, R. G., Freeman, T., McMorrow, L., Thomson, Z., Kitson-Wind, K., and Lee, H. (1999). Chromosomes Exhibit Preferential Positioning in Nuclei of Quiescent Human Cells. J. Cel. Sci. 112, 525-535. doi:10.1242/jcs.112.4.525

Nakamura-Ishizu, A., Takubo, K., Fujioka, M., and Suda, T. (2014). Megakaryocytes Are Essential for Hsc Quiescence through the Production of Thrombopoietin. Biochem. biophysical Res. Commun. 454, 353-357. doi:10.1016/j.bbrc.2014.10.095

Ni, F., Yu, W.-M., Wang, X., Fay, M. E., Young, K. M., Qiu, Y., et al. (2019). Ptpn21 Controls Hematopoietic Stem Cell Homeostasis and Biomechanics. Cell stem cell 24, 608-620. doi:10.1016/j.stem.2019.02.009

Okada, S., Leda, M., Hanna, J., Savage, N. S., Bi, E., and Goryachev, A. B. (2013). Daughter Cell Identity Emerges from the Interplay of Cdc42, Septins, and Exocytosis. Develop. Cel 26, 148-161. doi:10.1016/j.devcel.2013.06.015

Paglini, G., Peris, L., Diez-Guerra, J., Quiroga, S., and Cáceres, A. (2001). The Cdk5-p35 Kinase Associates with the Golgi Apparatus and Regulates Membrane Traffic. EMBO Rep. 2, 1139-1144. doi:10.1093/embo-reports/ kve250

Pagliuso, A., Tham, T. N., Stevens, J. K., Lagache, T., Persson, R., Salles, A., et al. (2016). A Role for Septin 2 in Drp1-mediated Mitochondrial Fission. EMBO Rep. 17, 858-873. doi:10.15252/embr.201541612

Pan, F., Malmberg, R. L., and Momany, M. (2007). Analysis of Septins across Kingdoms Reveals Orthology and New Motifs. BMC Evol. Biol. 7, 103. doi:10.1186/1471-2148-7-103

Paridaen, J. T. M. L., Wilsch-Bräuninger, M., and Huttner, W. B. (2013). Asymmetric Inheritance of Centrosome-Associated Primary Cilium Membrane Directs Ciliogenesis after Cell Division. Cell 155, 333-344. doi:10.1016/j.cell.2013.08.060

Park, H.-O., Bi, E., Pringle, J. R., and Herskowitz, I. (1997). Two Active States of the Ras-Related Bud1/Rsr1 Protein Bind to Different Effectors to Determine Yeast Cell Polarity. Proc. Natl. Acad. Sci. 94, 4463-4468. doi:10.1073/pnas.94.9.4463

Postnikoff, S. D. L., and Harkness, T. A. A. (2014). Replicative and Chronological Life-Span Assays. Springer, 223-227. doi:10.1007/978-1-4939-0799-1_17

Rittmeyer, E. N., Daniel, S., Hsu, S.-C., and Osman, M. A. (2008). A Dual Role for Iqgap1 in Regulating Exocytosis. J. Cel. Sci. 121, 391-403. doi:10.1242/ jcs.016881
Roche, B., Arcangioli, B., and Martienssen, R. (2017). Transcriptional Reprogramming in Cellular Quiescence. RNA Biol. 14, 843-853. doi:10.1080/15476286.2017.1327510

Rujano, M. A., Bosveld, F., Salomons, F. A., Dijk, F., Van Waarde, M. A. W. H., Van Der Want, J. J. L., et al. (2006). Polarised Asymmetric Inheritance of Accumulated Protein Damage in Higher Eukaryotes. Plos Biol. 4, e417. doi:10.1371/journal.pbio.0040417

Sadian, Y., Gatsogiannis, C., Patasi, C., Hofnagel, O., Goody, R. S., Farkasovský, M., et al. (2013). The Role of Cdc42 and Gicl in the Regulation of Septin Filament Formation and Dissociation. Elife 2, e01085. doi:10.7554/eLife.01085

Sagot, I., Pinson, B., Salin, B., and Daignan-Fornier, B. (2006). Actin Bodies in Yeast Quiescent Cells: an Immediately Available Actin reserve? $M B o C$ 17, 4645-4655. doi:10.1091/mbc.e06-04-0282

Sandrock, K., Bartsch, I., Bläser, S., Busse, A., Busse, E., and Zieger, B. (2011). Characterization of Human Septin Interactions. Characterization Hum. septin interactions 392, 751-761. doi:10.1515/BC.2011.081

Schmidt, K., and Nichols, B. J. (2004). Functional Interdependence between Septin and Actin Cytoskeleton. BMC Cel Biol 5, 43-13. doi:10.1186/1471-2121-5-43

Senger, K., Marka, G., Soller, K., Sakk, V., Florian, M. C., and Geiger, H. (2017). Septin 6 Regulates Engraftment and Lymphoid Differentiation Potential of Murine Long-Term Hematopoietic Stem Cells. Exp. Hematol. 55, 45-55. doi:10.1016/j.exphem.2017.07.005

Shcheprova, Z., Baldi, S., Frei, S. B., Gonnet, G., and Barral, Y. (2008). A Mechanism for Asymmetric Segregation of Age during Yeast Budding. Nature 454, 728-734. doi:10.1038/nature07212

Sheffield, P. J., Oliver, C. J., Kremer, B. E., Sheng, S., Shao, Z., and Macara, I. G. (2003). Borg/septin Interactions and the Assembly of Mammalian Septin Heterodimers, Trimers, and Filaments. J. Biol. Chem. 278, 3483-3488. doi:10.1074/jbc.m209701200

Shimada, Y., Wiget, P., Gulli, M.-P., Bi, E., and Peter, M. (2004). The Nucleotide Exchange Factor Cdc24p May Be Regulated by Auto-Inhibition. Embo J 23, 1051-1062. doi:10.1038/sj.emboj.7600124.

Sopko, R., Huang, D., Smith, J. C., Figeys, D., and Andrews, B. J. (2007). Activation of the Cdc42p Gtpase by Cyclin-dependent Protein Kinases in Budding Yeast. Embo J. 26, 4487-4500. doi:10.1038/sj.emboj.7601847

Soroor, F., Kim, M. S., Palander, O., Balachandran, Y., Collins, R. F., Benlekbir, S., et al. (2021). Revised Subunit Order of Mammalian Septin Complexes Explains Their In Vitro Polymerization Properties. MBoC 32, 289-300. doi:10.1091/ mbc.e20-06-0398

Spiliotis, E. T., and McMurray, M. A. (2020). Masters of Asymmetry - Lessons and Perspectives from 50 Years of Septins. MBoC 31, 2289-2297. doi:10.1091/ mbc.e19-11-0648

Spokoini, R., Moldavski, O., Nahmias, Y., England, J. L., Schuldiner, M., and Kaganovich, D. (2012). Confinement to Organelle-Associated Inclusion Structures Mediates Asymmetric Inheritance of Aggregated Protein in Budding Yeast. Cel Rep. 2, 738-747. doi:10.1016/j.celrep.2012.08.024

Sun, D., Luo, M., Jeong, M., Rodriguez, B., Xia, Z., Hannah, R., et al. (2014). Epigenomic Profiling of Young and Aged Hscs Reveals Concerted Changes during Aging that Reinforce Self-Renewal. Cell stem cell 14, 673-688. doi:10.1016/j.stem.2014.03.002

Sun, S., and Gresham, D. (2021). Cellular Quiescence in Budding Yeast. Yeast 38, 12-29. doi: $10.1002 /$ yea. 3545

Swayne, T. C., Zhou, C., Boldogh, I. R., Charalel, J. K., McFaline-Figueroa, J. R., Thoms, S., et al. (2011). Role for Cer and Mmrlp in anchorage of Mitochondria at Sites of Polarized Surface Growth in Budding Yeast. Curr. Biol. 21, 1994-1999. doi:10.1016/j.cub.2011.10.019

Tada, T., Simonetta, A., Batterton, M., Kinoshita, M., Edbauer, D., and Sheng, M. (2007). Role of Septin Cytoskeleton in Spine Morphogenesis and Dendrite Development in Neurons. Curr. Biol. 17, 1752-1758. doi:10.1016/ j.cub.2007.09.039

Takizawa, P. A., DeRisi, J. L., Wilhelm, J. E., and Vale, R. D. (2000). Plasma Membrane Compartmentalization in Yeast by Messenger Rna Transport and a Septin Diffusion Barrier. Science 290, 341-344. doi:10.1126/ science.290.5490.341

Tanaka-Takiguchi, Y., Kinoshita, M., and Takiguchi, K. (2009). Septin-mediated Uniform Bracing of Phospholipid Membranes. Curr. Biol. 19, 140-145. doi:10.1016/j.cub.2008.12.030 
Targa, B., Klipfel, L., Cantaloube, I., Salameh, J., Benoit, B., Poüs, C., et al. (2019). Septin Filament Coalignment with Microtubules Depends on SEPT9_i1 and Tubulin Polyglutamylation, and Is an Early Feature of Acquired Cell Resistance to Paclitaxel. Cell Death Dis 10, 54-14. doi:10.1038/s41419-019-1318-6

Vannini, N., Campos, V., Girotra, M., Trachsel, V., Rojas-Sutterlin, S., Tratwal, J., et al. (2019). The NAD-Booster Nicotinamide Riboside Potently Stimulates Hematopoiesis through Increased Mitochondrial Clearance. Cell Stem Cell 24 (3), 405-418. doi:10.1016/j.stem.2019.02.012

Wang, J.-B., Sonn, R., Tekletsadik, Y. K., Samorodnitsky, D., and Osman, M. A. (2009). Iqgap1 Regulates Cell Proliferation through a Novel Cdc42-Mtor Pathway. J. Cel. Sci. 122, 2024-2033. doi:10.1242/jcs.044644

Wang, X., Fujimaki, K., Mitchell, G. C., Kwon, J. S., Della Croce, K., Langsdorf, C., et al. (2017). Exit from Quiescence Displays a Memory of Cell Growth and Division. Nat. Commun. 8, 321-411. doi:10.1038/s41467-017-00367-0

Wang, X., Tsai, J.-W., Imai, J. H., Lian, W.-N., Vallee, R. B., and Shi, S.-H. (2009b). Asymmetric Centrosome Inheritance Maintains Neural Progenitors in the Neocortex. Nature 461, 947-955. doi:10.1038/nature08435

Weems, A., McMurray, M., and Barral, Y. (2017). The Step-wise Pathway of Septin Hetero-Octamer Assembly in Budding Yeast. eLife 6, e23689. doi:10.7554/ eLife.23689

Werner-Washburne, M., Braun, E., Johnston, G. C., and Singer, R. A. (1993). Stationary Phase in the Yeast saccharomyces Cerevisiae. Microbiol. Rev. 57, 383-401. doi:10.1128/mr.57.2.383-401.1993

Wilson, A., Laurenti, E., Oser, G., van der Wath, R. C., Blanco-Bose, W., Jaworski, M., et al. (2008). Hematopoietic Stem Cells Reversibly Switch from Dormancy to Self-Renewal during Homeostasis and Repair. Cell 135, 1118-1129. doi:10.1016/j.cell.2008.10.048

Xie, Y., Vessey, J. P., Konecna, A., Dahm, R., Macchi, P., and Kiebler, M. A. (2007). The Gtp-Binding Protein Septin 7 Is Critical for Dendrite Branching and Dendritic-Spine Morphology. Curr. Biol. 17, 1746-1751. doi:10.1016/j.cub.2007.08.042

Xu, J., Ji, J., and Yan, X.-H. (2012). Cross-talk between Ampk and Mtor in Regulating Energy Balance. Crit. Rev. Food Sci. Nutr. 52, 373-381. doi:10.1080/10408398.2010.500245

Yamazaki, S., Ema, H., Karlsson, G., Yamaguchi, T., Miyoshi, H., Shioda, S., et al. (2011). Nonmyelinating Schwann Cells Maintain Hematopoietic Stem Cell
Hibernation in the Bone Marrow Niche. Cell 147 (5), 1146-1158. doi:10.1016/ j.cell.2011.09.053

Yang, J., McCormick, M. A., Zheng, J., Xie, Z., Tsuchiya, M., Tsuchiyama, S., et al. (2015). Systematic Analysis of Asymmetric Partitioning of Yeast Proteome between Mother and Daughter Cells Reveals "Aging Factors" and Mechanism of Lifespan Asymmetry. Proc. Natl. Acad. Sci. USA 112, 11977-11982. doi:10.1073/pnas.1506054112

Yang, L., Wang, L., Geiger, H., Cancelas, J. A., Mo, J., and Zheng, Y. (2007b). Rho GTPase Cdc42 Coordinates Hematopoietic Stem Cell Quiescence and Niche Interaction in the Bone Marrow. Proc. Natl. Acad. Sci. 104, 5091-5096. doi:10.1073/pnas.0610819104

Yang, L., and Zheng, Y. (2007a). Cdc42: a Signal Coordinator in Hematopoietic Stem Cell Maintenance. Cell cycle 6, 1444-1449. doi:10.4161/cc.6.12.4371

Yusuf, I., and Fruman, D. A. (2003). Regulation of Quiescence in Lymphocytes. Trends Immunology 24, 380-386. doi:10.1016/s1471-4906(03)00141-8

Zhang, H., Pan, K.-H., and Cohen, S. N. (2003). Senescence-specific Gene Expression Fingerprints Reveal Cell-type-dependent Physical Clustering of Up-Regulated Chromosomal Loci. Proc. Natl. Acad. Sci. 100, 3251-3256. doi:10.1073/pnas.2627983100

Conflict of Interest: The authors declare that the research was conducted in the absence of any commercial or financial relationships that could be construed as a potential conflict of interest.

Publisher's Note: All claims expressed in this article are solely those of the authors and do not necessarily represent those of their affiliated organizations, or those of the publisher, the editors and the reviewers. Any product that may be evaluated in this article, or claim that may be made by its manufacturer, is not guaranteed or endorsed by the publisher.

Copyright $\odot 2021$ Schuster and Geiger. This is an open-access article distributed under the terms of the Creative Commons Attribution License (CC BY). The use, distribution or reproduction in other forums is permitted, provided the original author(s) and the copyright owner(s) are credited and that the original publication in this journal is cited, in accordance with accepted academic practice. No use, distribution or reproduction is permitted which does not comply with these terms. 